\title{
Stability Analysis of Steel Lining at Pressure Diversion Tunnel Collapse Zone during Operating Period
}

\author{
Ming Xiao ${ }^{1,2}$ and Chen Zhao ${ }^{1,2}$ \\ ${ }^{1}$ State Key Laboratory of Water Resources and Hydropower Engineering Science, Wuhan University, Wuhan 430072, China \\ ${ }^{2}$ Key Laboratory of Rock Mechanics in Hydraulic Structural Engineering, Wuhan University, Ministry of Education, \\ Wuhan 430072, China \\ Correspondence should be addressed to Chen Zhao; lutme@foxmail.com
}

Received 2 March 2017; Revised 9 March 2017; Accepted 19 March 2017; Published 30 March 2017

Academic Editor: Fabrizio Greco

\begin{abstract}
Copyright ( 2017 Ming Xiao and Chen Zhao. This is an open access article distributed under the Creative Commons Attribution License, which permits unrestricted use, distribution, and reproduction in any medium, provided the original work is properly cited.
\end{abstract}

\begin{abstract}
At the collapse zone, the effects of the thickness of the consolidation grouting layer and the water pressure on the steel lining are vital to the stability of steel-lined pressure diversion tunnels. In this paper, a joint element and the load-sharing ratio of the consolidation layer are introduced to investigate the joint load-bearing characteristics of the steel lining and the consolidation layer and to determine a suitable consolidation layer thickness; a coupling method for simulating the hydromechanical interaction of the reinforced concrete lining is adopted to investigate the effect of internal water exosmosis on the seepage field at the collapse zone and to determine the external water pressure on the steel lining. In the case of a steel-lined pressure diversion tunnel, a numerical simulation is implemented to analyse the effect of the thickness of the consolidation layer and the distribution of the seepage field under the influence of internal water exosmosis. The results show that a $10 \mathrm{~m}$ thick consolidation layer and the adopted antiseepage measures ensure the stability of the steel lining at the collapse zone under internal and external water pressure. These research results provide a reference for the design of treatment measures for large-scale collapses in steel-lined pressure tunnels.
\end{abstract}

\section{Introduction}

During the excavation of large-section hydraulic tunnels under complex geological conditions, collapses are relatively common geological disasters that have relatively significant detrimental impacts on tunnel construction and operation. For nonpressure hydraulic tunnels, the goal of a collapse treatment, similar to that for mountain tunnels and coalmine tunnels, is to ensure the stability of the surrounding rocks at the collapse zone by strengthening the support [1-5]. For pressure tunnels, the goal of a collapse treatment is to ensure the safe operation of the tunnel at the collapse zone under the effect of the internal and external water pressure during the operating period in addition to ensuring the stability of the surrounding rocks at the collapse zone during the construction period. For a small-scale collapse, the collapse cavity is usually treated by backfilling it completely $[6,7]$. The backfill material and the intact surrounding rocks are treated as a whole, thereby ensuring that the stability of the lining structure still meets the original design requirements. However, if the method of complete backfilling is adopted to treat a large-scale collapse, a series of problems, such as the requirement for a large amount of backfill, high costs, and difficult implementation, will arise. Therefore, a largescale collapse is sometimes treated by consolidation grouting of the loose collapse body above the tunnel within a certain thickness range [8]. Unlike the treatment measure of complete backfilling, the implementation of the consolidation grouting treatment measure presents the following different set of problems.

(1) The stability of the steel lining at the collapse zone under the internal water pressure during the operating period: during the operation of a pressure tunnel, internal water pressure is the primary load borne jointly by the lining, the concrete layer, and the surrounding rocks [9]. However, after a loose collapse body of a certain thickness above the 
tunnel is subjected to consolidation grouting, there is a cavity above the consolidation layer formed in the process. As a result, the internal water pressure at the arch crown is borne only by the steel lining, the concrete layer, and the consolidation layer. The resulting decrease in the thickness of the joint load-bearing structures will have an impact on their mechanical characteristics, even leading to damage of the consolidation layer or an uneven stress distribution at the top of the steel lining, which have adverse impacts on the safe operation of the steel-lined pressure tunnel at the collapse zone. Therefore, it is required to determine a suitable thickness of the consolidation layer and ensure the stability of the steel lining under the internal water pressure.

(2) The stability of the steel lining at the collapse zone under the external water pressure during the operating period: the presence of a collapse cavity alters the thickness and continuity of the cover layer above the tunnel. In addition, the cavity, as the potential seepage boundary, also alters the distribution of the seepage field. As a result, the external water pressure on the steel lining at the collapse zone cannot be directly estimated by the groundwater level and the reduction coefficient of the external water pressure. In the case investigated herein, the reinforced concrete lining is adopted at the preceding part of the pressure tunnel. The cracking of the reinforced concrete lining under the internal water pressure will result in the internal water flowing outside the tunnel through the cracks [10-12], which in turn will affect the seepage field at the entire collapse zone. In addition, the external water pressure on the steel lining at the collapse zone will also undergo a change, thereby affecting the stability of the steel lining at the collapse zone. Therefore, it is required to determine the external water pressure on the steel lining and design the corresponding antiseepage measures to ensure that the external water pressure is less than the critical external water compressive resistance of the adopted steel lining.

The aforementioned two problems are relatively less frequently quantificationally analysed when designing the treatment of the large-scale collapses that occur in the steellined pressure diversion tunnel. With respect to the design of the thickness of the consolidation layer and the analysis of the effectiveness of the collapse treatment during the operating period, most designs are based on engineering experience. Therefore, to address the aforementioned two problems, a joint element and a coupling method for simulating the hydromechanical interaction of the reinforced concrete lining are adopted, which consider the effects of the joint load-bearing characteristics of the steel lining and the consolidation layer and the internal water exosmosis on the stability of the steel lining at the collapse zone. In this paper, a case study of the large-scale collapse in pressure diversion tunnel of Hua'an hydropower station is conducted. Based on the actual conditions of the large-scale collapse, a support system was employed consisting of the pipe umbrella arch and steel grid arch, combined with a consolidation grouting treatment of the loose collapse body in the collapse cavity. In addition, a numerical simulation is implemented to study the joint load-bearing characteristics of the steel lining and the consolidation layer and the distribution characteristics of the seepage field at the collapse zone and then to determine the thickness of the consolidation layer and the external water pressure on the steel lining.

\section{Collapse Treatment Measures}

2.1. General Information regarding the Collapse. Hua'an hydropower station is located in Fujian Province, China. The pressure diversion tunnel lies between the surge shaft and the powerhouse. The center axial elevation of the tunnel is $32.0 \mathrm{~m}$. The length of the pressure tunnel is $148.1 \mathrm{~m}$. The preceding $25.0 \mathrm{~m}$ of the pressure tunnel is a transition section from sections $0+00.0 \mathrm{~m}$ to $0+25.0 \mathrm{~m}$, where the diameter of the excavation cross section changes from $10.5 \mathrm{~m}$ to $9.2 \mathrm{~m}$ gradually, and the thickness of the reinforced concrete lining is $1.0 \mathrm{~m}$. After section $0+25.0 \mathrm{~m}$, the steel lining is adopted. The inner diameter of the steel lining is $7.2 \mathrm{~m}$, and the thickness is $28.0 \mathrm{~mm}$. The longitudinal section and cross sections of the tunnel are shown in Figure 1.

When the excavation face was advanced at section $0+37.0 \mathrm{~m}$, the weathered sandy soil was exposed at the left side of the crown. Subsequently, the schistose collapsing block fell out. During the urgent supporting, the collapse became serious and the scope of the collapse spread to the right side of the excavation face. The volume of the collapse body in the tunnel was approximately $2700 \mathrm{~m}^{3}$; according to the area of the excavation section and the length of the collapse body in the tunnel, the height of the cavity above the tunnel might reach $30.0 \mathrm{~m}$. At collapse zone, the strength of rock is weaker than that at noncollapse zone; the surrounding rock is broken and cut by a lot of structural planes, resulting in a number of blocks that are not conducive to the stability; the blasting excavation reduces the strength of the structural planes; under the effects of the gravity and the unloading, the blocks moves toward the tunnel; the structural plane's strength is further reduced, eventually leading to collapse.

\subsection{Support and Consolidation Grouting at the Collapse Zone.} Based on the actual conditions of the tunnel collapse in the Hua'an project, the treatment measures were designed as follows (in Figures 1 and 2).

2.2.1. Pipe Umbrella Arch Support. First, steel pipes with the diameter of $108.0 \mathrm{~mm}$, the spacing in the circumferential direction of $1.0 \mathrm{~m}$, the external angle of 30 degrees, and the length of $7.0 \mathrm{~m}$ were inserted at the crown in range of 120 degrees, and then grout was injected through the pipes as the first consolidation grouting. Second, steel pipes with the diameter of $42.0 \mathrm{~mm}$, the external angle of 15 degrees, and the length of $7.0 \mathrm{~m}$ were inserted between each of the two larger diameter pipes, followed by injection of grout as the second consolidation grouting.

2.2.2. Reserved Core Soil Excavation. As the stability of the surrounding rocks at the collapse zone was poor and they were easy to collapse during the excavation, the reserved core soil excavation method was adopted. First, the excavation footage was controlled in $50 \mathrm{~cm}$, and a certain length of the 


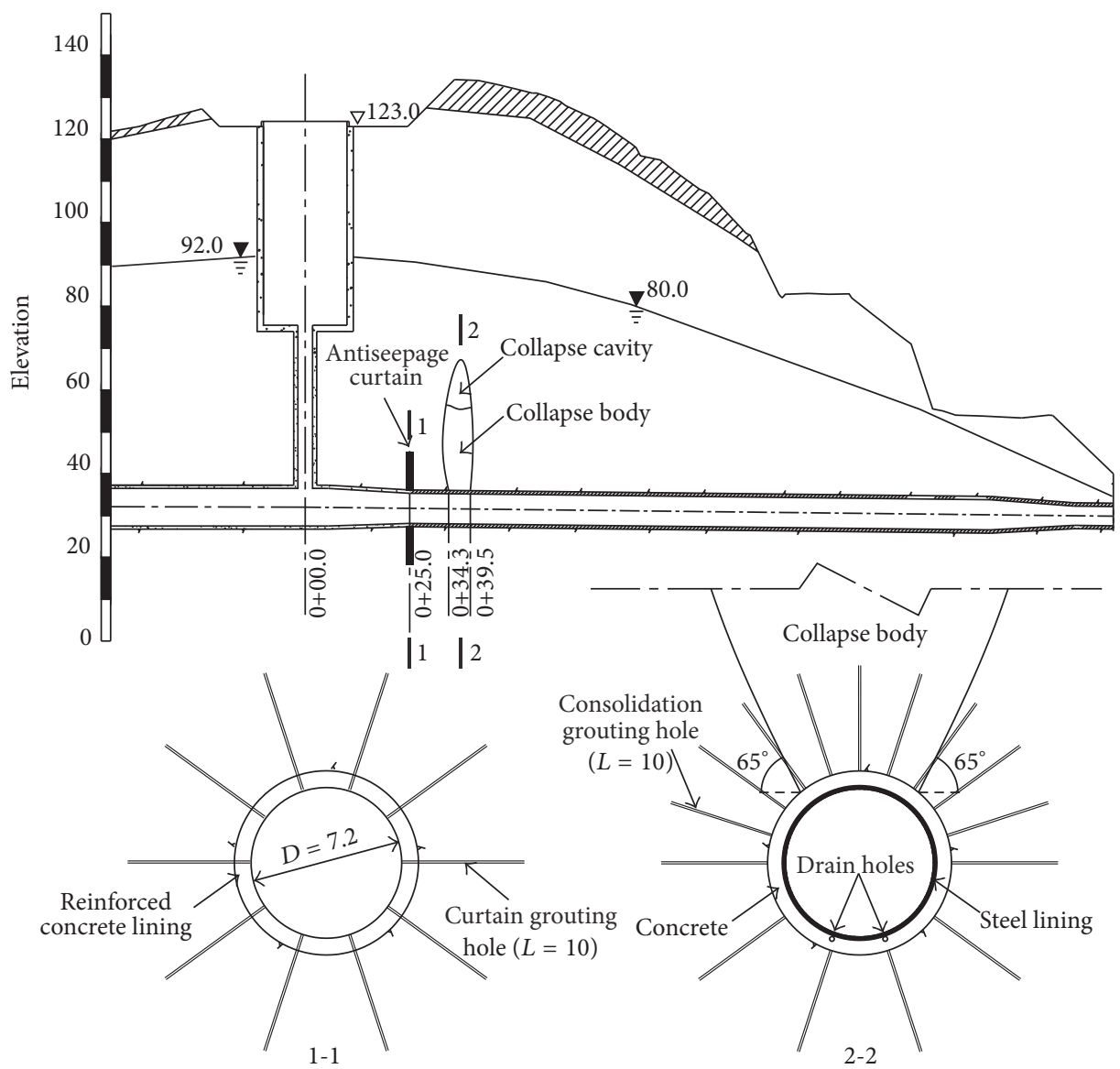

FIGURE 1: Longitudinal section and cross sections of the tunnel (unit: $\mathrm{m}$ ).

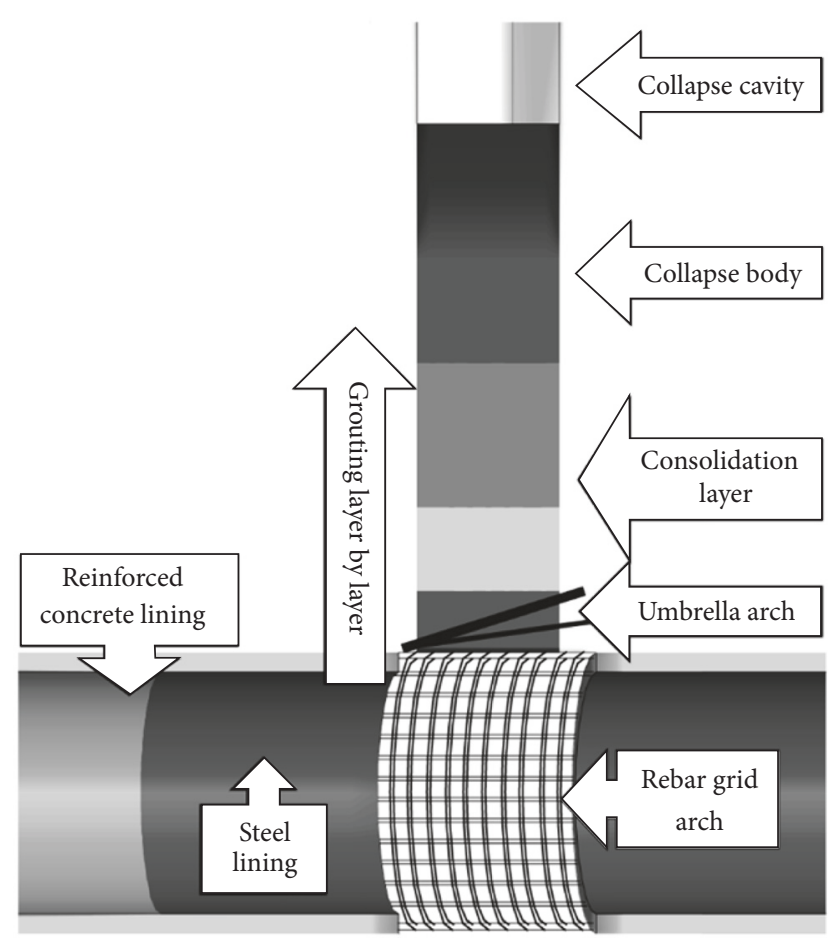

FIgURE 2: Schema of the collapse treatment measures. core soil was reserved. Then, after two excavation cycles, the reserved core soil was excavated. After each excavation cycle completed, the concrete was sprayed onto the excavation face immediately to prevent it from contacting with damp air and improve the self-stability of the excavation face.

2.2.3. Rebar Grid Arch Support. $\Phi 32$ screw thread steel was adopted as the main rebar and the spacing was $0.5 \mathrm{~m}$. Ф25 screw thread steel was adopted as the connection rebar and the spacing was $0.6 \mathrm{~m}$. The rebar grid arch was installed after each excavation cycle. The concrete was sprayed onto the rebar grid arch, and the thickness of shotcrete layer was $20.0 \mathrm{~cm}$. After ten excavation cycles, the installation of steel grid arch support was completed.

2.2.4. Consolidation Grouting of the Collapse Body in the Collapse Cavity. The collapse body and the surrounding rocks were divided into three grouting layers. The collapse body (from sections $0+32.0 \mathrm{~m}$ to $0+42.0 \mathrm{~m}$ ): ten grouting holes were arranged at the crown with an equal interval at each row; the spacing of rows was $2.0 \mathrm{~m}$; the depths of the grouting deepened gradually with $2.5 \mathrm{~m}, 5.0 \mathrm{~m}$, and $10.0 \mathrm{~m}$. The surrounding rocks (from sections $0+00.0 \mathrm{~m}$ to $0+60.0 \mathrm{~m})$ : ten grouting holes are arranged with an equal interval at each row; the spacing of rows was $2.0 \mathrm{~m}$; the depths 
of the grouting also deepened gradually with $2.5 \mathrm{~m}, 5.0 \mathrm{~m}$, and $10.0 \mathrm{~m}$. In addition, the grouting pressure increased gradually, followed by the depth of the grouting layers: the pressure of $0.3 \mathrm{MPa}$ was adopted in the depth of 0.0 to $2.5 \mathrm{~m}, 0.7 \mathrm{MPa}$ corresponding to 2.5 to $5.0 \mathrm{~m}$, and $1.5 \mathrm{MPa}$ corresponding to 5.0 to $10.0 \mathrm{~m}$.

2.2.5. The Antiseepage Curtain and Drain Holes. Two rows of curtain grouting holes were set at the junction between the reinforced concrete lining and the steel lining. The spacing between the two rows was $1.0 \mathrm{~m}$. Two lines of drain holes were set at the bottom of the steel lining from section $0+25.0 \mathrm{~m}$, and the diameter of the drain holes is $5.0 \mathrm{~cm}$.

\subsection{Monitoring Analysis of Pressure Tunnel during the Con-} struction Period. There were many uncertainties during the construction at the collapse zone. The rock mass at the collapse zone had a low strength and a low inherent bearing capacity; therefore, there was still the risk of instability. To address this issue, the deformation of the surrounding rocks at the collapse zone was monitored to ensure the safety and stability of the tunnel during the construction period. Two convergence measuring lines and one settlement measuring line were set at the collapse zone.

In Figure 3, the convergence curve and settlement curve of the tunnel at the collapse zone shows that the settlement curves fluctuated up and down affected by the construction disturbance during the collapse treatment period; the settlement increased constantly, and the maximum value was about $18.0 \mathrm{~mm}$; then, the displacement of the tunnel tended to be stable and the crown settlement stabilised at $13.0 \mathrm{~mm}$. In addition, the convergence curve shows that the last convergence value was about $8.0 \mathrm{~mm}$. The monitoring results indicate that the strengthening measures employed could ensure the stability of the tunnel during the construction period.

\section{Analysis Methods for Joint Load-Bearing Characteristic}

After the loose collapse body in the collapse cavity is subjected to consolidation grouting, a consolidation layer with a certain thickness is formed, and the cavity is not fully backfilled, affecting the joint load-bearing characteristics. In addition, the gap between the steel lining and the consolidation layer is also a key that affects the joint load-bearing characteristics. To address these problems, based on the finite element theory, the present study introduces a joint element and the load-sharing ratio of the consolidation layer to investigate the joint load-bearing characteristics of the steel lining and the consolidation layer and determine the thickness of consolidation layer.

3.1. Numerical Simulation of a Joint Element. The concrete layer and the consolidation layer have a certain constraining effect on the steel lining. Factors such as construction and concrete shrinkage result in gap between the steel lining and the concrete layer. Under the internal water pressure, the steel

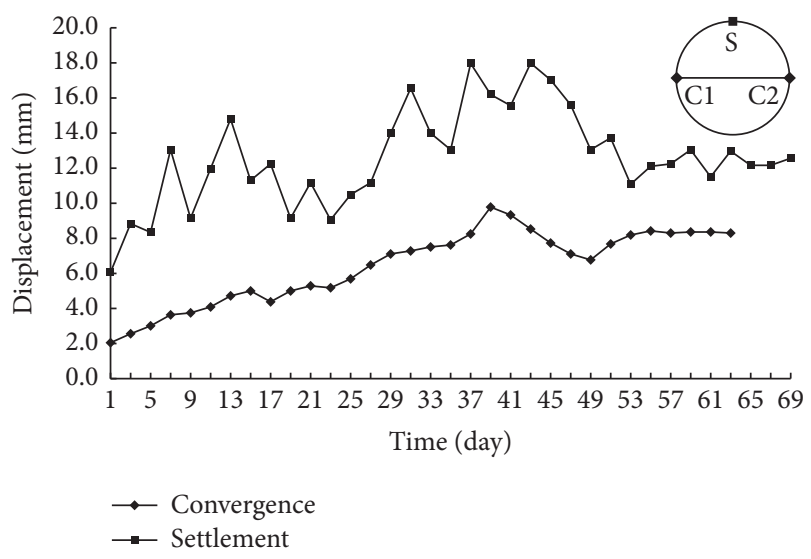

FIgURE 3: Measured convergence and settlement curves of the tunnel at section $0+28.0 \mathrm{~m}$.

lining has radial displacement. When the gap between the steel lining and the concrete layer is closed, the steel lining, the concrete layer, and the consolidation layer joint bear the load and simultaneously undergo deformation. In general, there is a stage at which the steel lining bears the load alone because of the gap. This stage continues until the steel lining fills the gap through deformation, at which time the steel lining and the concrete layer interact and jointly bear the load with the consolidation layer. Therefore, a joint element is introduced into the numerical simulation [13]. The joint element is a thin gap element. When the steel lining is not in contact with the concrete layer, the joint element is filled with air. At this time, the parameters of the joint element are approximately equal to the parameters of air. When the steel lining is in contact with the concrete layer, the corresponding joint element changes to a solid concrete element. At this time, the parameters of the joint element are approximately equal to the parameters of the concrete.

There are three main steps for simulating the process of the steel lining touching the concrete layer with using hierarchical loading and the iteration method by changing plastic stiffness [14].

Step 1. The total load, $\{R\}$ (internal water pressure), is divided into an elastic load, $\left\{R_{e}\right\}$, and a plastic load, $\left\{R_{p}\right\}$, as follows:

$$
\begin{aligned}
\left\{R_{e}\right\} & =S\{R\}, \\
\left\{R_{p}\right\} & =(1-S)\{R\},
\end{aligned}
$$

where $S$ is the coefficient of elasticity, $\left\{R_{e}\right\}$ is evenly divided into $m^{\prime}$ number of levels, $\left\{R_{p}\right\}$ is divided into $m$ number of levels based on geometric weighting, and $m^{\prime}$ and $m$ are determined based on the calculation accuracy.

Step 2. After calculating the elastic load of each level, $\left\{R_{e}\right\}_{i}\left(i=1, \ldots, m^{\prime}\right)$, the nodal displacement, $\left\{\delta_{e}\right\}_{i}$, and the stress of the element, $\left\{\sigma_{e}\right\}_{i}$, are calculated using

$$
\begin{aligned}
& \left\{\delta_{e}\right\}_{i}=\left[K_{e}\right]^{-1}\left\{R_{e}\right\}_{i}, \\
& \left\{\sigma_{e}\right\}_{i}=\left[D_{e}\right][B]\left\{\delta_{e}\right\}_{i},
\end{aligned}
$$


where $\left[D_{e}\right]$ is the elastic stress matrix and $[B]$ is the strain matrix.

Whether the steel lining element is in contact with the concrete layer element can be judged by the relative difference between the radial nodal displacement of the steel lining element and the radial nodal displacement of the concrete element at the joint after $\left\{R_{e}\right\}_{i}$ is calculated. If the relative displacement difference equals the joint width, the steel lining element is in contact with the concrete element. Once the steel lining element comes into contact with the concrete element, the joint element is changed to a solid concrete element, and the elastic stiffness matrix of the structure, $\left[K_{e}\right]$, is reassembled. Then, the calculation of the elastic load at the next level, $\left\{R_{e}\right\}_{i+1}$, is performed. The calculation, followed by judgment and stiffness matrix assembling, is performed until the calculation and judgment of all the levels of the elastic loads, $\left\{R_{e}\right\}_{i}\left(i=1, \ldots, m^{\prime}\right)$, are completed.

Step 3. For the plastic load of each level, $\left\{R_{p}\right\}_{i}(i=1, \ldots, m)$, based on the iteration method by changing plastic stiffness, the nodal displacement of the element, $\left\{\delta_{n}\right\}_{i}$, and the elasticplastic stress increment, $\left\{\Delta \sigma_{e p}\right\}_{i}$, are calculated by the following iterative equations.

The incremental displacement is calculated using

$$
\left\{\Delta \delta_{n}\right\}_{i}=\left[K_{e}\right]^{-1}\left[K_{p}\right] \alpha_{n-1}\left\{\Delta \delta_{n-1}-\Delta h_{n-1}\right\}_{i} .
$$

The modified displacement is calculated using

$$
\left\{\Delta h_{n}\right\}_{i}=\left[K_{e}\right]^{-1}\left[K_{p}\right] \alpha_{n-1}\left\{\Delta \delta_{n}\right\}_{i} .
$$

The total displacement is calculated using

$$
\left\{\delta_{n}\right\}_{i}=\left\{\delta_{n-1}\right\}_{i}+\left\{\Delta \delta_{n}\right\}_{i}+\left\{\Delta h_{n}\right\}_{i} .
$$

The acceleration factor is calculated using

$$
\alpha_{n}=\frac{\left\{\Delta \delta_{n}\right\}_{i}^{T}\left(\left\{\Delta \delta_{n}\right\}_{i}+\left\{\Delta h_{n}\right\}_{i}\right)}{\left\{\Delta \delta_{n}\right\}_{i}^{T}\left\{\Delta \delta_{n}\right\}_{i}} .
$$

The elastic-plastic stress increment is calculated using

$$
\begin{aligned}
\left\{\Delta \sigma_{e p}\right\}_{i} & =S\left[D_{e}\right]\left\{\Delta \varepsilon_{e}\right\}_{i}+\sum_{i=1}^{n}\left[D_{e p}\right]\left\{\Delta \varepsilon_{P}\right\}_{i}, \\
\left\{\Delta \varepsilon_{P}\right\}_{i} & =\frac{(1-S)\{\Delta \varepsilon\}}{N},
\end{aligned}
$$

where $\left[K_{e}\right]$ is the elastic stiffness matrix; $\left[K_{p}\right]$ is the plastic stiffness matrix; $\{\Delta \varepsilon\}$ is the strain determined using the elastic mechanical approach when $\left\{R_{p}\right\}_{i}$ is calculated; $\left[D_{e}\right]$ and $\left[D_{e p}\right]$ are the elastic stress matrix and the elastic-plastic stress matrix, respectively; $n$ is the number of iterations of the plastic load increment, $\left\{R_{p}\right\}_{i}$; and $N$ is the number used to equally divide the difference.

After the calculation of the elastic load $\left\{R_{e}\right\}$, for the steel lining element that is not yet in contact with the concrete layer, whether it will be in contact with the concrete element at the joint under the plastic load of each level, $\left\{R_{p}\right\}_{i}$, can be determined using the same method (as in Step 2 above) based on the relative displacement difference after each iteration. Once the steel lining is in contact with the concrete element, the corresponding joint element changes to a solid concrete element, the elastic stiffness matrix of the structure, $\left[K_{e}\right]$, is reassembled, and the next iteration of the plastic load of the level, $\left\{R_{p}\right\}_{i}$, is conducted. The plastic stiffness matrix of the structure, $\left[K_{p}\right]$, is assembled based on the critical stress condition after the iteration of the plastic load of each level, $\left\{R_{p}\right\}_{i}$. This calculation, followed by a judgment of whether the gap is closed or open and stiffness matrix assembling, is repeated until the iterative calculation of the plastic load of the level $\left\{R_{p}\right\}_{i}$ is completed. Afterwards, the iteration and judgment calculation of the plastic load of $(i+1)$ th level are performed successively.

3.2. Load-Sharing Ratio of Consolidation Layer. In this study, based on the concept of the sharing ratio of surrounding rocks (the percentage difference between the stress on the buried pipe and the stress on the exposed pipe under the effect of the same internal pressure), the load-sharing ratio of the consolidation layer is defined as $\lambda=1-\sigma / \sigma_{0}$, where $\sigma$ is the maximum tensile stress on the steel lining after consolidation grouting and $\sigma_{0}$ is the maximum tensile stress on the steel lining without consolidation grouting. By defining the loadsharing ratio of the consolidation layer in this manner, the portion of the load shared by the consolidation layer with different thicknesses when it bears the load together with the steel lining can be estimated, thereby facilitating the determination of a suitable consolidation layer thickness to ensure the safe operation of the steel lining under the internal water pressure.

\section{Coupling Method for the Hydromechanical Interaction of Reinforced Concrete Lining}

Under the internal water pressure, the seepage field and stress field in the concrete lining interact. After the concrete lining enters the plastic damage stage from the elastic stage, with the extent of damage of the concrete increasing, cracks occur in the lining, which increases the permeability of the concrete and generates larger seepage pressure, thereby aggravating damage in the concrete lining [15-17]. In this paper, a hydromechanical coupling model for the reinforced concrete lining under the internal water pressure is established. The finite element iteration method with changing plastic stiffness is applied and the hydraulic-mechanical interaction in the process of lining cracking is considered.

4.1. Stress Field of the Concrete Lining. In this paper, the concrete is treated as an elastoplastic material. And a damage coefficient, $D$, is introduced to represent the extent of damage of the concrete as follows:

$$
D=1-\exp \left(-R \varepsilon^{\mathrm{Ep}}\right),
$$

where $R$ is the damage constant and $\varepsilon^{\mathrm{Ep}}$ is the equivalent plastic strain. 
The differential expression for the stress increment of the concrete in the damage state is as follows:

$$
\begin{aligned}
\left\{d \sigma_{i j}\right\}_{D} & =\left(\left[H_{e}\right]-\left[H_{D}\right]\right)\left\{d \varepsilon_{i j}\right\}-S_{i j} d D \\
{\left[H_{D}\right] } & =\left(1-D+\frac{D}{3} \delta_{i j}\right)\left[H_{p}\right]+\left[D-\frac{D}{3} \delta_{i j}\right]\left[H_{e}\right], \\
S_{i j} & =\sigma_{i j}-\frac{\sigma_{k k} \delta_{i j}}{3}
\end{aligned}
$$

where $\left[H_{e}\right]$ is the elastic stress matrix, $\left[H_{D}\right]$ is the damage stress matrix, $\left[H_{p}\right]$ is plastic stress matrix, $\sigma_{k k}$ is three normal stresses, and $\delta_{i j}$ is Kronecker delta.

Drucker-Prager yield criterion is used for the concrete. And the iteration method by changing plastic stiffness is used to solve the stress field. The load increment at each stage is applied to the structure as follows:

$$
\left[K_{e}\right]\left\{\Delta \delta_{i}\right\}_{j}=\left\{\Delta F_{s i}\right\}+\left\{\Delta P_{i}\right\}+\left[K_{D}\right]\left\{\Delta \delta_{i}\right\}_{j-1},
$$

where $\left[K_{e}\right]$ and $\left[K_{D}\right]$ are the elastic stiffness matrix and damage stiffness matrix, respectively; $\left\{\Delta \delta_{i}\right\}_{j}$ and $\left\{\Delta \delta_{i}\right\}_{j-1}$ are the displacement increments of current stage and last stage, respectively; $\left\{\Delta F_{s i}\right\}$ and $\left\{\Delta P_{i}\right\}$ are the seepage load increment of current stage and structural load increment of current stage, respectively.

After the concrete lining cracking, the constitutive relationship of the cracked element becomes anisotropic and the stress matrix of cracked element under local coordinate system can be obtained by [11]

$$
\begin{aligned}
& {\left[H^{\prime}\right]}
\end{aligned}
$$

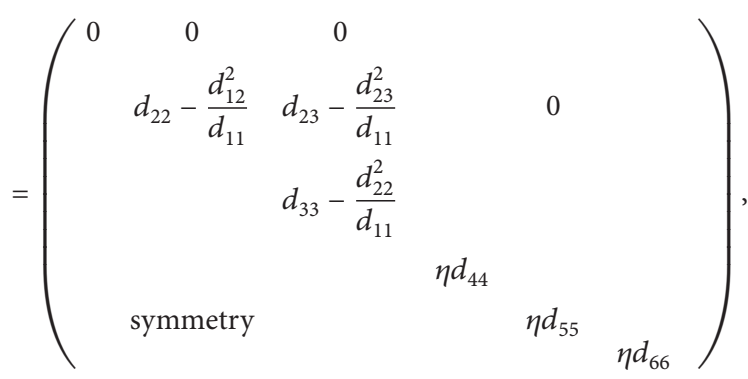

where $d_{11}=d_{22}=d_{33}=E_{c}(1-v) /(1+v)(1-2 v), d_{12}=d_{13}=$ $d_{23}=v E_{c} /(1+v)(1-2 v)$, and $d_{44}=d_{55}=d_{66}=E_{c} / 2(1+\nu)$; $\nu$ and $E_{c}$ are Poisson's ratio and elastic modulus of concrete, respectively; $\eta$ is the residual shear coefficient.

Then the modified stress matrix can be transferred into the global coordinate with using the coordinate transfer matrix.

4.2. Seepage Field of the Concrete Lining. According to Darcy's law, the basic equation of three-dimension stable seepage is as follows:

$$
\begin{aligned}
& \frac{\partial}{\partial X}\left(k_{x x} \frac{\partial H}{\partial X}\right)+\frac{\partial}{\partial Y}\left(k_{y y} \frac{\partial H}{\partial Y}\right)+\frac{\partial}{\partial Z}\left(k_{z z} \frac{\partial H}{\partial Z}\right) \\
& \quad=Q
\end{aligned}
$$

where $k_{x x}, k_{y y}$, and $k_{z z}$ are the main permeability coefficient, $Q$ is the seepage quantity of unit volume, and $H$ is the water head.

Based on the principle of FEM, the basic equation of three-dimension stable seepage of FEM is as follows:

$$
\left[K_{s}\right]\{H\}=\{A\},
$$

where $\left[K_{s}\right]$ is the seepage conductive matrix, $\{H\}$ is the unknown nodal water head vector, and $\{A\}$ is the known nodal water head vector.

The seepage volume load generated by the hydraulic gradient of the seepage field is applied on the element nodes, resulting in a change in the stress field of the lining structure. The seepage load is calculated as follows:

$$
\left\{F_{s}\right\}=-\iiint_{\Omega} \gamma_{w}[N]\left(\begin{array}{c}
\frac{\partial H}{\partial x} \\
\frac{\partial H}{\partial y} \\
\frac{\partial H}{\partial z}-1
\end{array}\right) d \Omega,
$$

where $\gamma_{w}$ is the bulk density of water and $[N]$ is the matrix of the element shape function.

In this paper, there are three kinds of boundary conditions for the three-dimension stable seepage.

(1) The water head boundary condition (the first boundary condition) is

$$
H=\phi_{0} \quad\left(\text { on } \Gamma_{1}\right),
$$

where $\phi_{0}$ is the prescribed water head on the boundary $\Gamma_{1}$.

(2) The flux boundary condition (the second boundary condition) is

$$
q=q_{0} \quad\left(\text { on } \Gamma_{2}\right)
$$

where $q_{0}$ is the prescribed flux on the boundary $\Gamma_{2}$.

(3) The potential seepage boundary condition of Signorini's type [18] is

$$
\begin{aligned}
H & \leq z, \\
q & \leq 0 \\
(H-z) q & =0
\end{aligned}
$$

$\left(\right.$ on $\left.\Gamma_{s}\right)$,

where $z$ is the vertical coordinate.

4.3. Coupling Mechanism. Under the internal water pressure, cracks in the concrete lining are generally caused by the actual strain of the concrete element exceeding the ultimate tensile strain. When cracks occur in the lining, seepage flow in the concrete will be governed by these cracks. To represent the interaction between crack and permeability, the modified cubic law [19] is adopted:

$$
\begin{aligned}
k_{f} & =\frac{\gamma}{12 \mu c} W_{\max }^{2}, \\
c & =1+8.8\left(\frac{\Delta}{d}\right)^{1.5},
\end{aligned}
$$


where $\gamma$ and $\mu$ are the bulk density and dynamic viscosity factor of water, respectively; $c$ is the roughness modification coefficient of crack; $\Delta$ is the average raised height of granule in crack, which can be determined by tests; $d$ is the hydraulic diameter of crack, which is twice the crack width. [20]:

The following formula is used to estimate the crack width

$$
\begin{aligned}
W_{\max } & =4 \varepsilon_{s} t_{e}, \\
t_{e} & =0.725 \sqrt[3]{b A},
\end{aligned}
$$

where $W_{\max }$ is the maximal crack width, $\varepsilon_{s}$ is the strain of steel, $A=2 b r$, and $b$ and $r$ are the thickness of protection layer and spacing of steel, respectively.

After the concrete cracking, there is a sliding displacement between the rebar and the concrete as a result of the decrease in the bearing capacity of the concrete, the concrete only bears the corresponding load with its residual bearing capacity, and the remaining load is borne by the steel rebar. The portion of the load allocated to the steel rebar and the concrete is based on the damage coefficient of the concrete, $D$. Therefore, when the cracks occur in the lining, the strain of reinforcement can be described as [10]

$$
\varepsilon_{s}=\frac{(1-\rho+n \rho) D \varepsilon}{(\eta-\eta \rho+n \rho D)},
$$

where $n=E_{s} / E_{c}$ is the elasticity modulus ratio of steel to concrete; $\rho$ is the reinforcement ratio; $\varepsilon$ is the maximum principal strain of lining element.

Substituting (19)-(21) into (18), the permeability after the lining cracking can be solved.

In addition, the uncracked concrete could be regarded as an isotropic material, and, based on the Kozeny-Carman formula, the permeability of the uncracked concrete, $K$, can be described as follows [21]:

$$
K=K_{0} \frac{\left(1+\varepsilon_{V} / n_{0}\right)^{3}}{1+\varepsilon_{V}},
$$

where $n_{0}$ is initial porosity, $\varepsilon_{V}$ is volumetric strain, and $K_{0}$ is initial permeability of the concrete.

\subsection{Coupling Iteration Process}

(A) Calculate the seepage field and get the seepage nodal loads $\left\{F_{s}\right\}$ by using (13) and (14).

(B) Apply $\left\{F_{s}\right\}$ into (10) to get the new stress field.

(C) Calculate a new damage coefficient, $D$, according to (8), modify the stress matrix of the cracked concrete elements according to (11), and calculate the new permeability of concrete according to (18) and (22).

(D) Repeat the calculation steps (A) to (C) until the stress field satisfies the convergence condition.

\section{Stability Analysis of the Steel Lining during the Operating Period}

In this section, in a case study of the steel-lined pressure diversion tunnel in the Hua'an hydropower station, the adopted analysis and simulation methods are used to investigate the joint load-bearing characteristics of the steel lining and the consolidation layer and the distribution of the seepage field at the collapse zone, and, then, the thickness of the consolidation layer and the external water pressure on the steel lining at the collapse zone are determined. The reasonableness and effectiveness of the determined consolidation layer thickness and the adopted antiseepage measures are also investigated to ensure that the steel lining still meets the original design requirements.

5.1. Boundary Conditions and Material Parameters. As shown in Figure 4, the numerical model is composed of 59,014 eightnode hexahedral elements and 63,705 nodes. It includes the pressure diversion tunnel, the reinforced concrete lining, the steel lining, the grouting zone of the surrounding rocks, the consolidation grouting layer of the collapse body, a collapse cavity above the tunnel, joint elements around the steel lining, drain holes, and an antiseepage curtain. $Z$ coordinate of each point in the model is equal to that point's actual elevation. The model's lengths along $x$-, $y$-, and $z$-axes are 173.0, 124.0, and $209.0 \mathrm{~m}$, respectively. The bottom of the model is at $-49.0 \mathrm{~m}$, and the model's maximum elevation is $160.0 \mathrm{~m}$.

The boundary conditions are that all the surfaces except the top surface are fixed in the normal direction and that the top surface is free. The seepage boundaries are as follows: the upriver and downriver surfaces of the model are treated as the first seepage boundaries, and the water levels of the upstream and downstream surfaces are $91.0 \mathrm{~m}$ and $78.0 \mathrm{~m}$, respectively. Under the load rejection condition, the inner surface of the reinforced concrete lining is treated as the first seepage boundary, and the total head on the inner surface is $123.0 \mathrm{~m}$. The surfaces of the steel lining are impervious boundaries. The surfaces of the collapse cavity and the drain holes are treated as potential seepage boundaries.

The original ground stress is defined based on a selfweight stress field. The initial conditions for the operating period are determined after the tunnel has been excavated and the lining has been installed. Because of the limitation of the finite element method for simulating the process of tunnel collapse, the method of excavation-backfilling is adopted to approximately simulate the effect of collapse. The process of collapse is regarded as the excavation, and the remaining collapse body in the collapse cavity is result of backfilling. The support effects of the pipe umbrella arch and steel grid arch are simulated by the equivalent parameters method; that is, $E=E_{0}+A_{g} E_{g} / A_{c}$, where $E$ is the equivalent modulus, $E_{0}$ is the modulus of the elements around the support, $A_{g}$ is the cross-sectional area, $E_{g}$ is the modulus of the steel, and $A_{c}$ is the cross-sectional area of the steel. The steel lining is simulated as a linear elastic material. The parameters of the steel lining are as follows: the thickness is $28.0 \mathrm{~mm}$, the elastic modulus is $210.0 \mathrm{GPa}$, Poisson's ratio is 


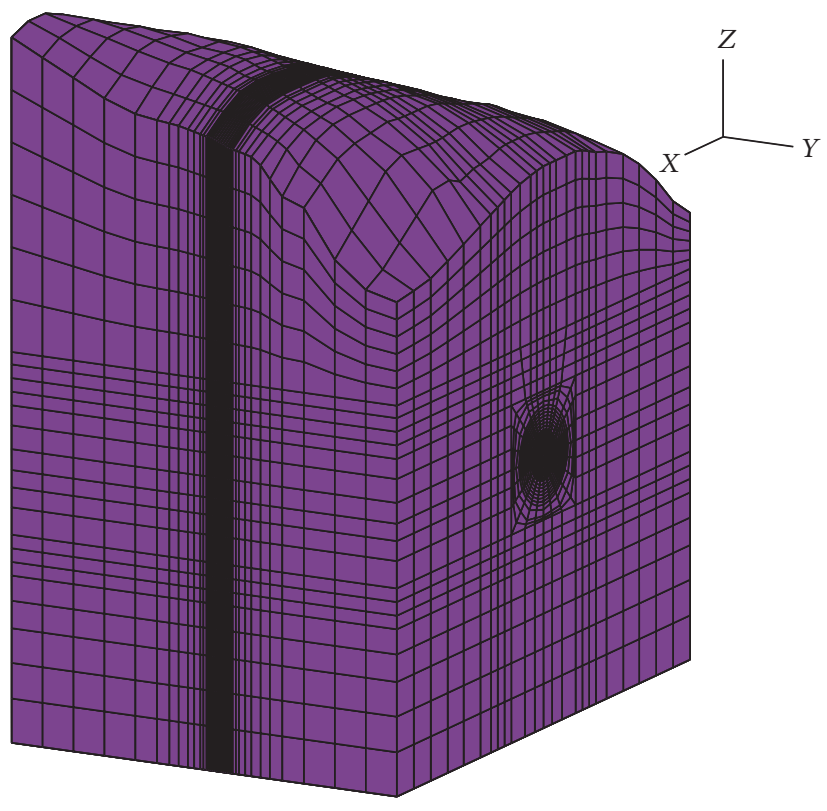

(a)

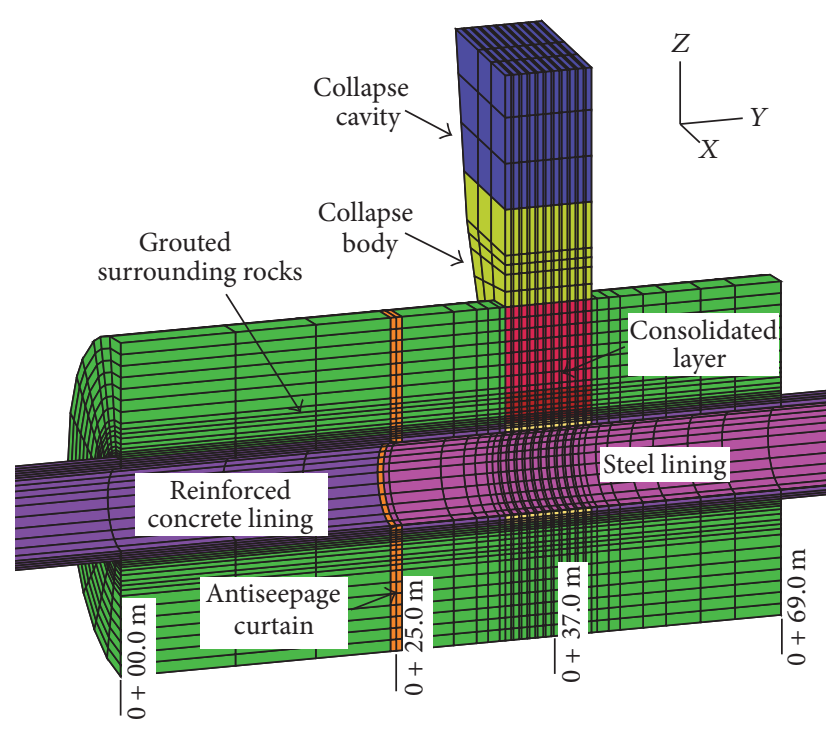

(b)

Figure 4: 3D finite element mesh for the numerical model: (a) the numerical model mesh and (b) the mesh at the collapse zone.

0.3 , the critical external compressive resistance to buckling is $0.68 \mathrm{MPa}$ according to Design Code for Steel Penstocks of Hydroelectric Stations in China (NB/T 35056-2015) and the volumetric weight is $78.5 \mathrm{kN} \cdot \mathrm{m}^{-3}$. The joint width $\Delta=\Delta_{0}+$ $\Delta_{S}+\Delta_{R}=0.69 \mathrm{~mm}$, where $\Delta_{0}(=0.20 \mathrm{~mm})$ is the construction joint, $\Delta_{S}(=0.28 \mathrm{~mm})$ is the cold shrinkage joint of the steel lining, and $\Delta_{R}(=0.21 \mathrm{~mm})$ is the cold shrinkage joint of the surrounding rock. The parameters of the rebar in the reinforced concrete lining are as follows: the elastic modulus is $210.0 \mathrm{GPa}$, the reinforcement ratio is 0.02 , the thickness of the protection layer is $0.1 \mathrm{~m}$, and the spacing is $0.2 \mathrm{~m}$. The rock mass surrounding the tunnel is mainly weakly weathered medium-coarse granite, which is relatively compact and rigid. To obtain the mechanical parameters of the surrounding rocks, according to the Code for Rock Tests of Hydroelectric and Water Conservancy Engineering in China (SL264-2001), the designing institute collected core samples on the site and made them into the standard cylindrical specimens with $50 \mathrm{~mm}$ (in diameter) $\times 100 \mathrm{~mm}$ (in height). Then, the triaxial compression test was performed for each specimen. From the test results, the deformation modulus of the surrounding rocks is in the range of 8.0 to $10.0 \mathrm{GPa}$ and the deformation modulus of the surrounding rocks at the collapse zone is in the range of 3.0 to $5.0 \mathrm{GPa}$. Unlike the reason of collapse caused by the very low rock mass parameters and no selfstability, the main reason for this collapse is broken surrounding rock, developed structural planes, and blasting excavation disturbance. Therefore, although the rock mass parameters at collapse zone are lower than that at noncollapse zone, the structure of block at collapse zone is not too worse and the modulus is not too low. In the numerical calculation, the lower limit of the deformation modulus range was used. And the other parameters used are based on the information provided by the designing institute and experience with the project and [22]. The mechanical parameters used in the numerical simulation are given in Table 1 .

\subsection{Stability Analysis of the Steel Lining under Internal Water} Pressure. During the water filling operation, the maximum total head in the tunnel is $123.0 \mathrm{~m}$ under the load rejection condition. To study the joint load-bearing characteristics of the steel lining and the consolidation layer and determine the thickness of the consolidation layer of the collapse body above the tunnel, analyses with consolidation layer thicknesses ranging from $0 \mathrm{~m}$ (without consolidation grouting) to $30 \mathrm{~m}$ (i.e., complete backfilling) are performed under the load rejection condition. The consolidation layer, in comparison with the surrounding grouted rocks, has a relatively low strength and a low inherent bearing capacity; therefore, this study focuses on the crown and the consolidation layer above the tunnel at the collapse zone.

The displacement on the top of the steel lining and the range of displacement (the difference between the maximum displacement and minimum displacement) of the steel lining with the consolidation layer thicknesses from $0 \mathrm{~m}$ to $30 \mathrm{~m}$ are shown in Figure 5. When the thickness of the consolidation layer above the tunnel increases from $0 \mathrm{~m}$ to $5 \mathrm{~m}$, the displacement on the top decreases significantly, from $2.04 \mathrm{~mm}$ to $1.27 \mathrm{~mm}$, and the range of displacement of the lining also decreases, which indicates that as the thickness of the consolidation layer increases, its ability to restrict the deformation of the steel lining becomes more remarkable and it is able to distribute the displacement on the steel lining more evenly. However, for thicknesses greater than $10 \mathrm{~m}$, as the thickness increases, the displacement of the top of the steel lining gradually converges, which indicates that there 
TABLE 1: Mechanical parameters of the materials.

\begin{tabular}{|c|c|c|c|c|c|c|}
\hline Materials & $\begin{array}{l}\text { Deformation } \\
\text { modulus/GPa }\end{array}$ & Poisson's ratio & Cohesion/MPa & $\begin{array}{l}\text { Friction } \\
\text { angle } /\left(^{\circ}\right)\end{array}$ & $\begin{array}{c}\text { Tensile } \\
\text { strength/MPa }\end{array}$ & $\begin{array}{c}\text { Permeability } \\
\text { coefficient/ } \\
\mathrm{m} \cdot \mathrm{s}^{-1}\end{array}$ \\
\hline Rock mass & 8.0 & 0.27 & 0.55 & 37.0 & 1.4 & $6 e-7$ \\
\hline $\begin{array}{l}\text { Grouted rock } \\
\text { mass }\end{array}$ & 10.0 & 0.26 & 0.80 & 40.0 & 1.6 & $2 e-7$ \\
\hline Collapse body & 3.0 & 0.32 & 0.27 & 33.0 & 0.6 & $6 e-5$ \\
\hline $\begin{array}{l}\text { Consolidation } \\
\text { layer }\end{array}$ & 5.0 & 0.29 & 0.45 & 35.5 & 1.0 & $6 e-6$ \\
\hline $\begin{array}{l}\text { Antiseepage } \\
\text { curtain }\end{array}$ & 10.0 & 0.26 & 0.80 & 40.0 & 1.6 & $1 e-9$ \\
\hline Concrete & 28.0 & 0.18 & 2.15 & 50.0 & 1.2 & $2 e-8$ \\
\hline
\end{tabular}

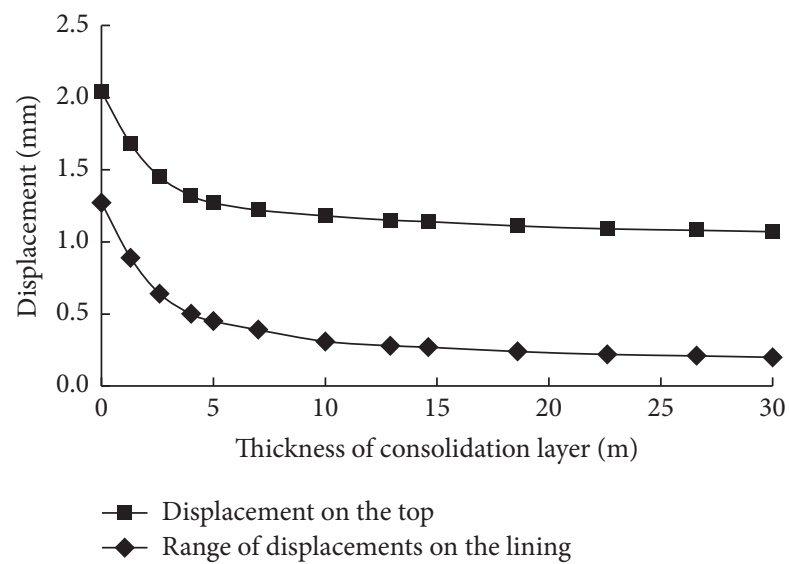

FIGURE 5: Displacements and the range of displacements of the steel lining at section $0+37.0 \mathrm{~m}$.

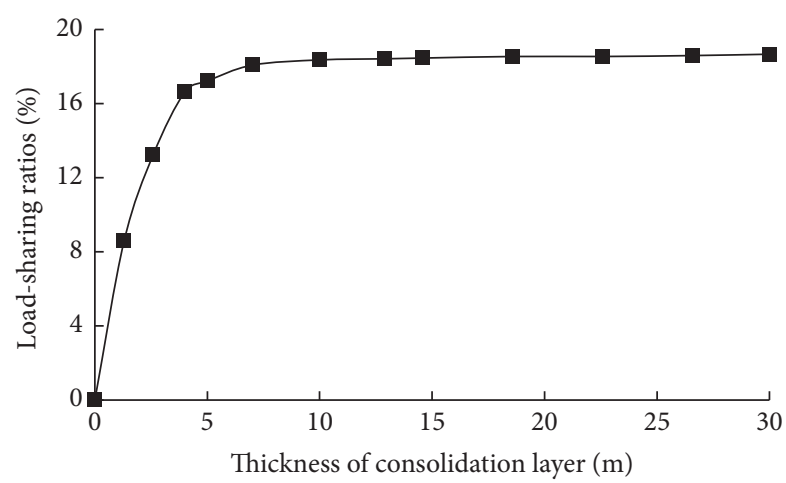

FIGURE 6: Load-sharing ratio of the consolidation layer.

is no obvious change in the consolidation layer's ability to restrict the steel lining when the thickness exceeds $10 \mathrm{~m}$.

The calculated load-sharing ratio of the consolidation with the consolidation layer thicknesses from $0 \mathrm{~m}$ to $30 \mathrm{~m}$ is shown in Figure 6. As the thickness of the consolidation layer increases from $0 \mathrm{~m}$ to $5 \mathrm{~m}$, the load-sharing capacity of the consolidation layer increases in an obvious trend. When the thickness exceeds $10 \mathrm{~m}$, the load-sharing ratio gradually converges. In addition, the load-sharing ratio of the $10 \mathrm{~m}$ thick consolidation layer is very close to that of the $30 \mathrm{~m}$ thick layer, which indicates that both consolidation grouting, which forms the $10 \mathrm{~m}$ thick consolidation layer, and complete backfilling share the load well.

From Figures 5 and 6, when the thickness of the consolidation layer exceeds $10 \mathrm{~m}$, there is no obvious change in the effect of the consolidation layer thickness on the steel lining; therefore, $10 \mathrm{~m}$ is considered the preliminary thickness.

The distributions of the tensile stress in the steel lining with 0 and $10 \mathrm{~m}$ thick consolidation layers are shown in Figure 7. Compared with a $0 \mathrm{~m}$ thick layer, when the layer is $10 \mathrm{~m}$ thick, the stress concentration on the top of the steel lining is significantly relieved, which indicates that the consolidation layer effectively improves the stress state of the steel lining and is conducive to its stability.

The distributions of the third and first principal stresses on a $10 \mathrm{~m}$ thick consolidation layer are shown in Figure 8. No stress concentration occurs in the consolidation layer and the stresses are distributed normally and evenly, which indicates that the consolidation layer is in a good stress state during the operating period.

As demonstrated by the results, when the steel lining and consolidation layer jointly bear the internal water pressure, the effect of the $10 \mathrm{~m}$ thick consolidation layer's load-sharing is obvious, which makes the distribution of the deformation and stress in the steel lining even. In addition, the consolidation layer is in a good stress state and does not damage, which ensures the structural stability of the consolidation layer itself. In general, when the steel lining and the $10 \mathrm{~m}$ thick consolidation layer jointly bear the internal water pressure, the steel lining is stable.

5.3. Stability Analysis of the Steel Lining under External Water Pressure. The critical external compressive resistance of the original design for steel lining is $0.68 \mathrm{MPa}$. If there is neither collapse nor internal water exosmosis, the external water pressure on the steel lining at the collapse zone is approximately $0.5 \mathrm{MPa}$. However, changes in the seepage field at the collapse zone caused by the collapse cavity and the aggravation of internal water flowing out to the rock 


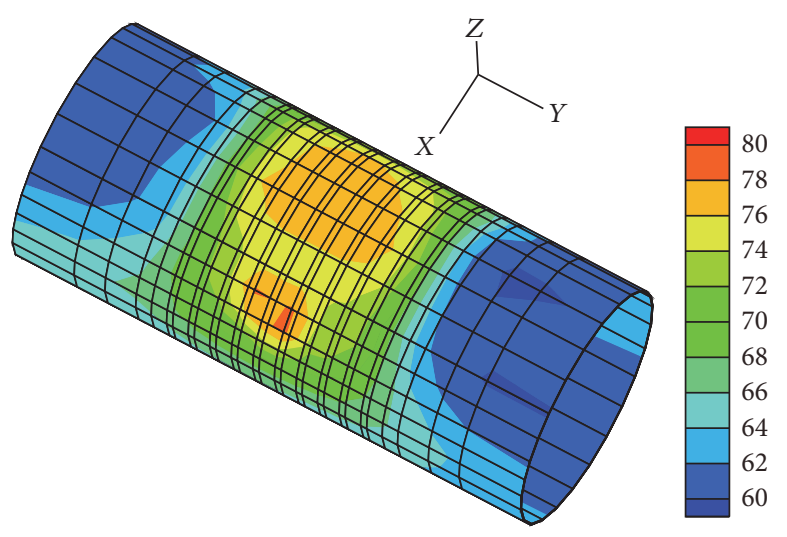

(a)

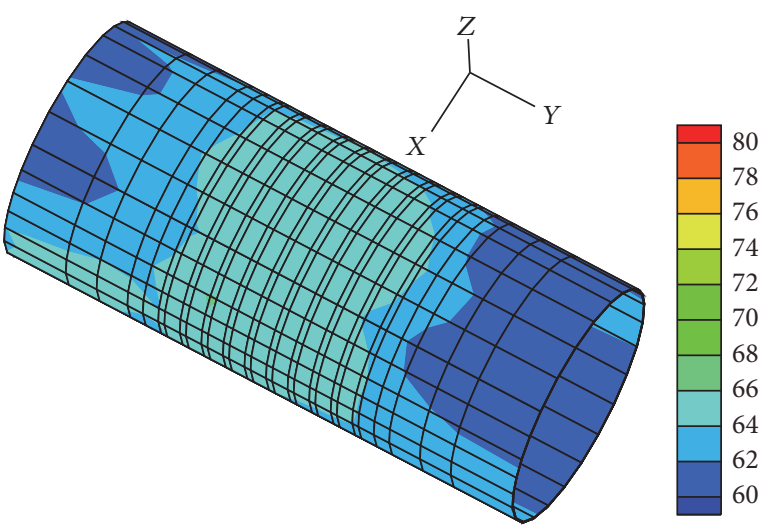

(b)

FIgURE 7: Tensile stress distributions of the steel lining at the collapse zone from sections $0+29.8 \mathrm{~m}$ to $0+46.3 \mathrm{~m}$ : (a) with $0 \mathrm{~m}$ thick consolidation layer and (b) with $10 \mathrm{~m}$ thick consolidation layer (unit: MPa).

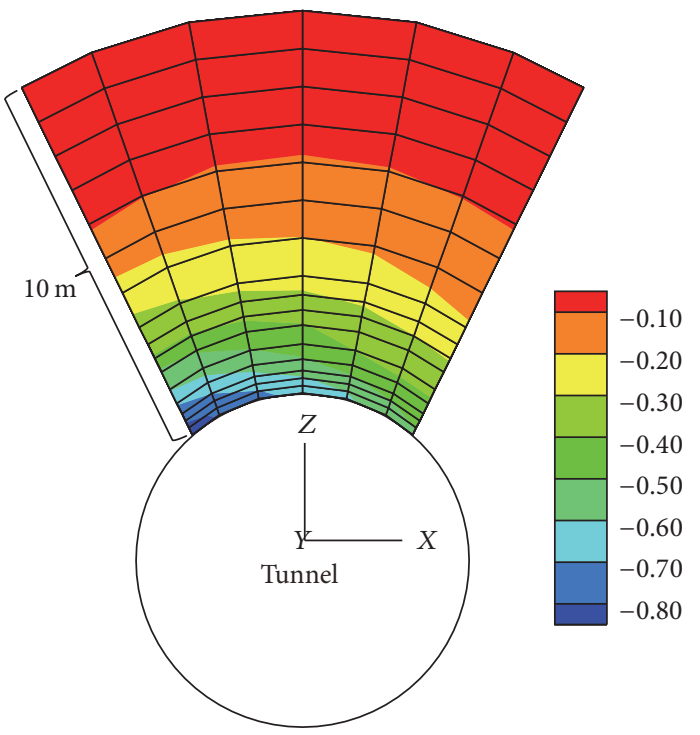

(a)

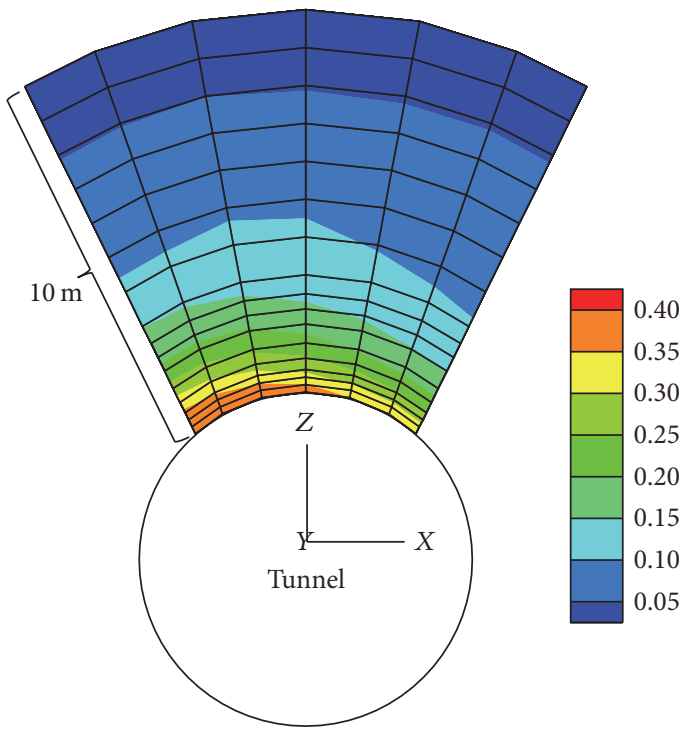

(b)

FIGURE 8: Stress distributions in the $10 \mathrm{~m}$ thick consolidation layer at section $0+37.0 \mathrm{~m}$ : (a) the third principal stress and (b) the first principal stress.

mass through the cracks in the reinforced concrete lining have significant influences on the external water pressure on the steel lining. Therefore, determining the external water pressure on the steel lining at the collapse zone is a key. In view of these considerations, based on the theory of coupled hydromechanical interaction of the reinforced concrete lining and with the influence of the cavity above the tunnel and the internal water exosmosis taken into account, the distribution of the seepage field at the collapse zone is investigated. Based on the calculated seepage field, suitable antiseepage measures are adopted to ensure that the external water pressure on the steel lining satisfies the requirements of the design specification during the operating period.

When the tunnel is quickly evacuated for inspection or another problem, the external water pressure caused by internal water exosmosis does not dissipate immediately, which results in high external water pressure on the steel lining, especially under the load rejection condition. Therefore, the load rejection condition is treated as the most unfavourable condition in this study. An analysis of the following three scenarios is performed under the load rejection condition and with consolidation grouting (in Table 2).

First, the results for the adopted coupling method are analysed. Figure 9 shows the distribution of the total head isolines in the concrete lining at section $0+10.8 \mathrm{~m}$ in scenario 1. In Figure 9, the isolines are distributed densely in the lining $(0.0-1.0 \mathrm{~m})$, and the value decreases quickly from the inner layer to the outer layer. The hydraulic gradient in the lining is approximately 5 .

Based on the coupling method, in scenario 1, the stress distribution in the concrete lining is analysed. Figure 10 shows the tensile stress distribution of the concrete lining 


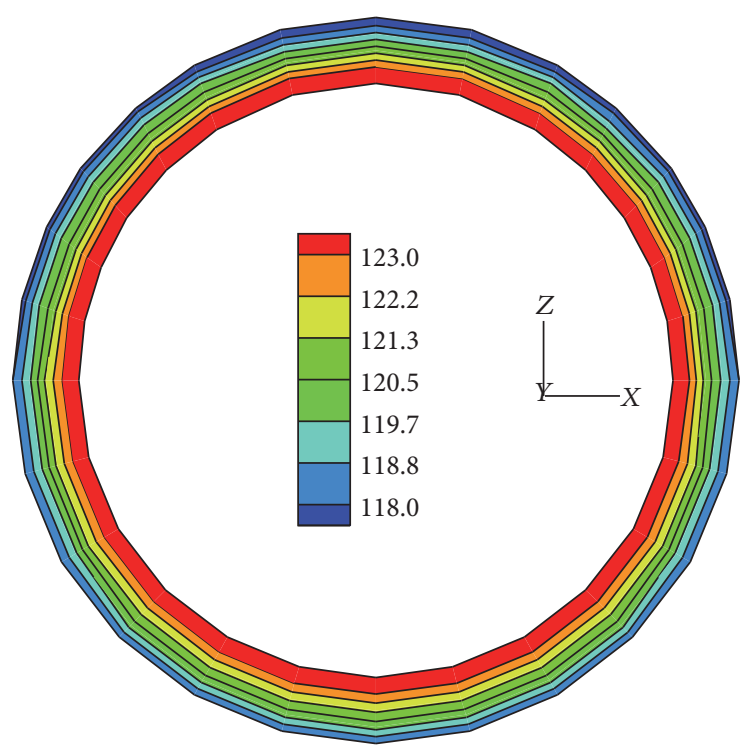

FIGURE 9: Distribution of the total head isolines in the concrete lining at section $0+10.8 \mathrm{~m}$ in scenario 1 (unit: $\mathrm{m}$ ).

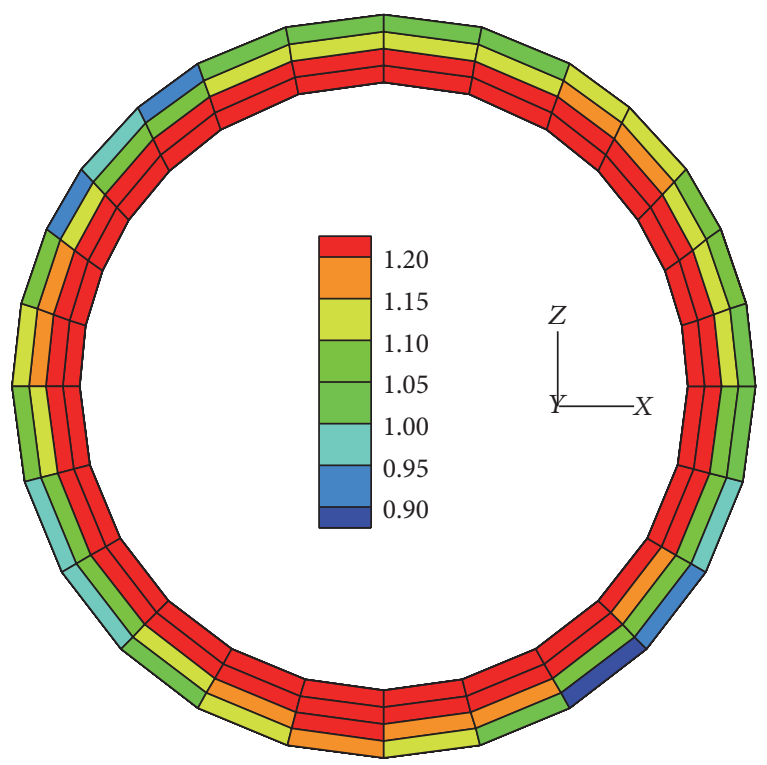

FIGURE 10: Tensile stress distribution of the concrete lining at section $0+10.8 \mathrm{~m}$ in scenario 1 (unit: $\mathrm{MPa}$ ).

at section $0+10.8 \mathrm{~m}$. The tensile stress in the lining ranges from $0.90 \mathrm{MPa}$ to $1.20 \mathrm{MPa}$. Figure 11 shows the crack width distribution of the concrete lining elements at section $0+10.8 \mathrm{~m}$. The distribution of the crack width coincides with the distribution of stress in the lining; the maximum crack width appears where the tensile stress is the greatest and no cracks occur in the outer layer of the concrete lining.

A comparison of the different scenarios is then performed. Figure 12 shows the distributions of the pressure head isolines in the seepage fields in the three scenarios. Because the upstream and downstream water levels are higher than

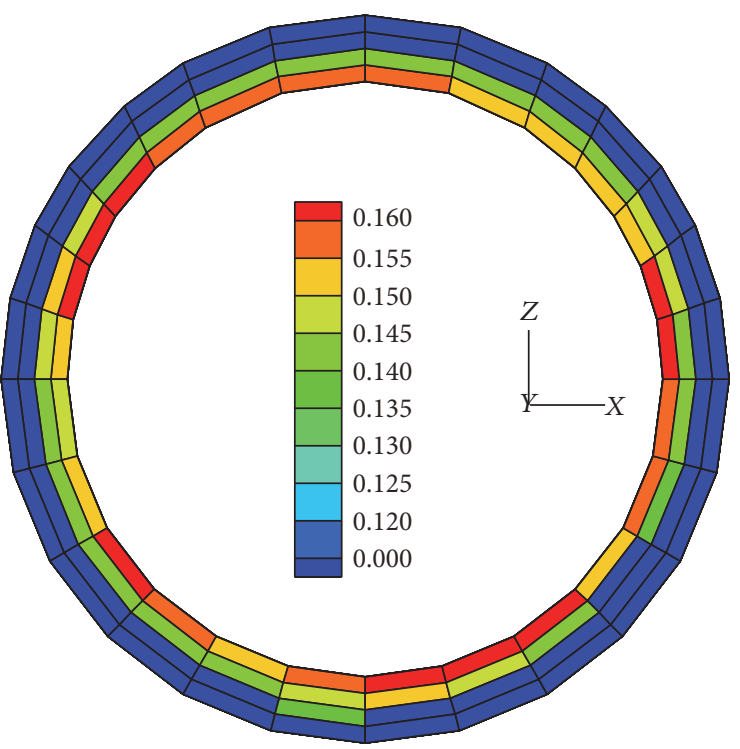

FIGURE 11: Crack width distribution of the concrete lining elements at section $0+10.8 \mathrm{~m}$ in scenario 1 (unit: $\mathrm{mm}$ ).

TABLE 2: Scenarios considered.

\begin{tabular}{lcc}
\hline Scenarios & Exosmosis condition & Antiseepage condition \\
\hline Scenario 1 & $\begin{array}{c}\text { With internal water } \\
\text { exosmosis }\end{array}$ & $\begin{array}{c}\text { Without antiseepage } \\
\text { measures }\end{array}$ \\
Scenario 2 & $\begin{array}{c}\text { Without internal water } \\
\text { exosmosis }\end{array}$ & $\begin{array}{c}\text { Without antiseepage } \\
\text { measures }\end{array}$ \\
Scenario 3 & $\begin{array}{c}\text { With internal water } \\
\text { exosmosis }\end{array}$ & $\begin{array}{c}\text { With antiseepage } \\
\text { measures }\end{array}$ \\
\hline
\end{tabular}

the elevation of the collapse cavity, the water flows into the cavity and the water level drops, which results in a U-shaped distribution of the seepage field, which indicates that the cavity affects the distribution of the seepage field and reduces the water head at the collapse zone.

Compared with scenario 2 , in scenario 1 , as the internal water exosmosis generates an internal source of seepage, the pressure head increases and the isolines are distributed densely in the grouting zone near the concrete lining and then affect the seepage field at the collapse zone. In Figure 13, the central angle, which corresponds to the arc length along the clockwise path from the top of the steel lining, is used as the abscissa. At the collapse zone, the external pressure head on the steel lining in scenario 1, as shown in Figure 13(a), is approximately $4 \mathrm{~m}$ larger than it is in scenario 2 . In addition, near the junction between the concrete lining and the steel lining, the external pressure head on the steel lining in scenario 1, as shown in Figure 13(b), is approximately $20 \mathrm{~m}$ greater than it is in scenario 2. Consequently, it is necessary to consider the influence of the collapse cavity and internal water exosmosis on the distribution of the seepage field at the collapse zone. 


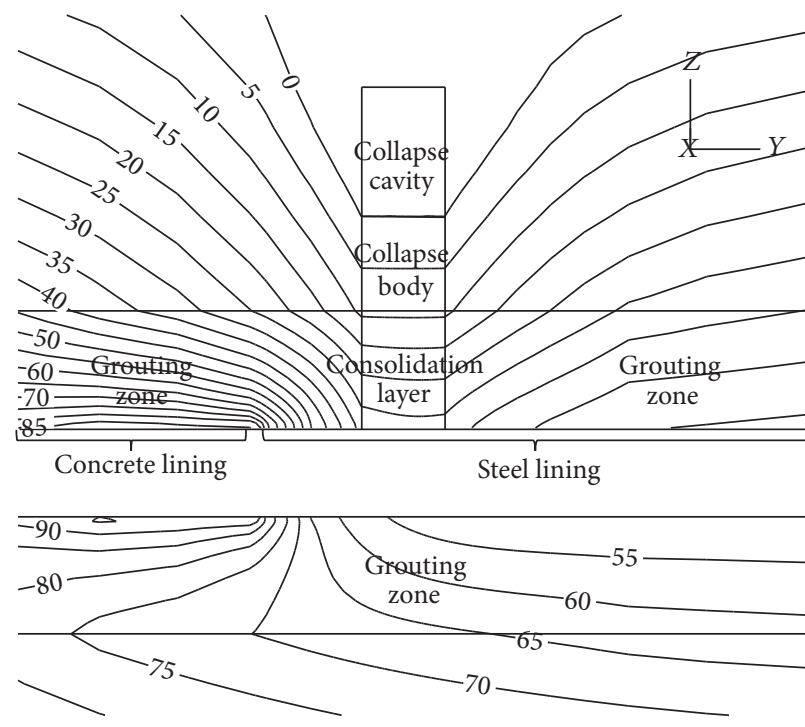

(a)

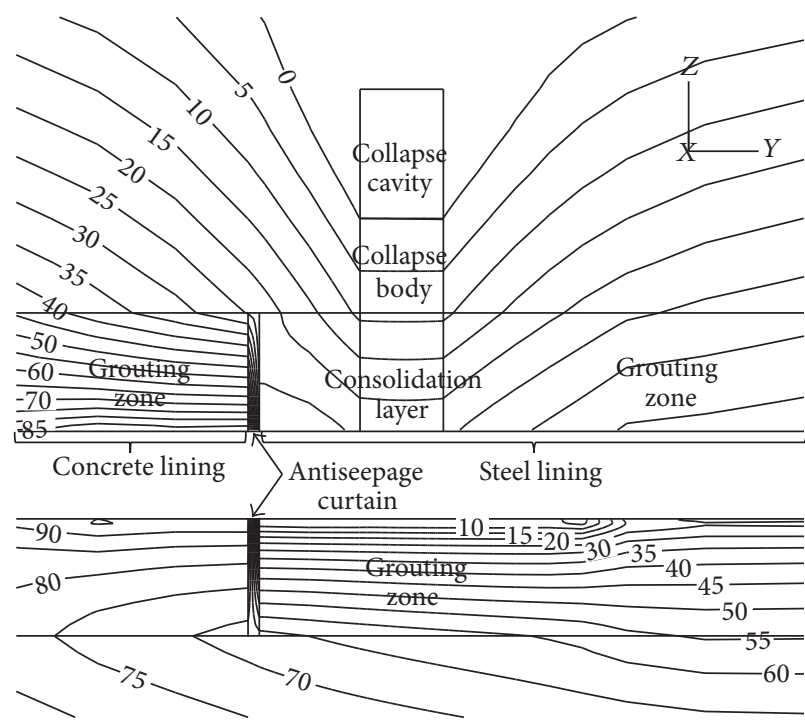

(c)
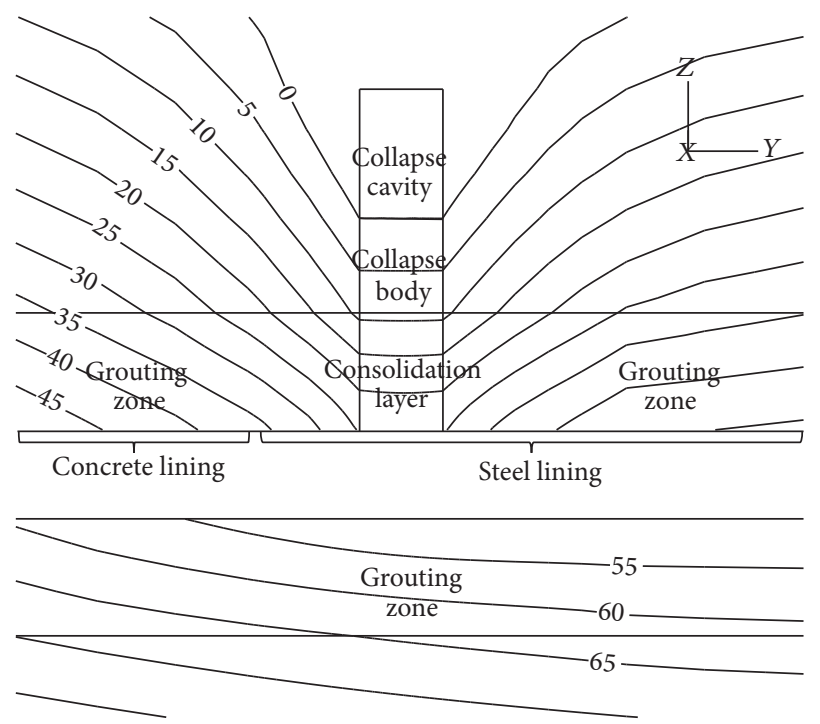

(b)

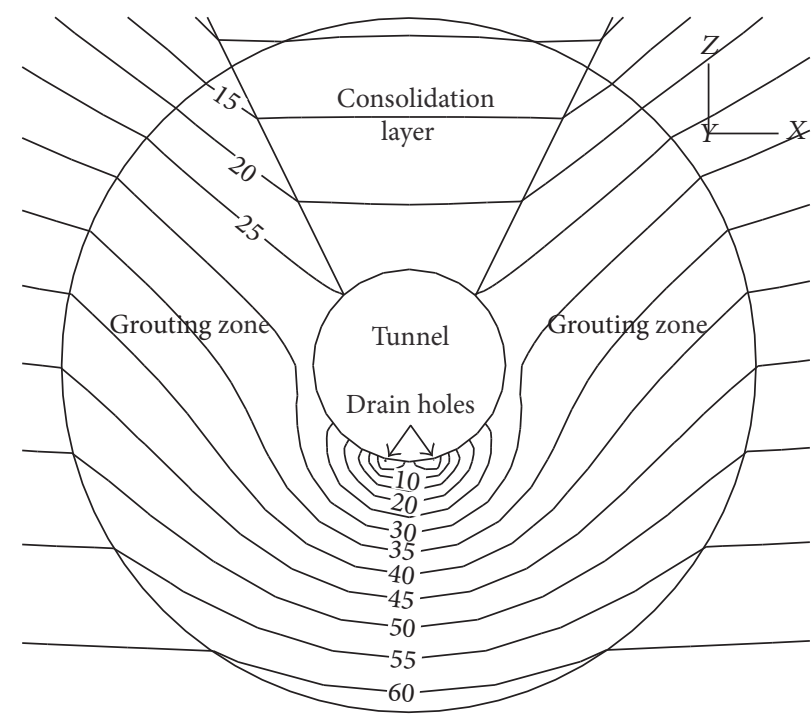

(d)

FIGURE 12: Distributions of the pressure head isolines: (a) along the tunnel axis in scenario 1; (b) along the tunnel axis in scenario 2; (c) along the tunnel axis in scenario 3 ; and (d) at section $0+37.0 \mathrm{~m}$ in scenario 3 (unit: $\mathrm{m}$ ).

Based on the distribution of the seepage field in scenario 1 , an antiseepage curtain is placed between the reinforced concrete lining and the steel lining to diminish the influence of internal water exosmosis on the collapse zone, and two rows of drain holes are placed at bottom of the steel lining to decrease the external water pressure on the steel lining.

With the antiseepage curtain and the drain holes, in scenario 3 , the maximum external pressure head on the steel lining at the collapse section decreases to $29.6 \mathrm{~m}$ from $54.3 \mathrm{~m}$, its value in scenario 1 (in Figure 13(a)). In addition, as shown in Figure 13(b), near the junction between the steel lining and the concrete lining, the maximum external pressure head on the steel lining also decreases from $72.9 \mathrm{~m}$ to $32.2 \mathrm{~m}(0.32 \mathrm{MPa})$, and the stability coefficient is 2.13 , which satisfies the requirement of China Standard Design Code 1.80. In scenario 3 (in Figure 12(c)), in the antiseepage curtain, the isolines are distributed densely and the hydraulic gradient is large, which indicates that the antiseepage curtain prevents seepage well. As shown in Figures 12(d) and 13, because external water is drained through the drain holes, the external water head near the drain holes decreases significantly.

From the above analyses, the internal water flowing out to the rock mass through the cracks in the concrete lining and the collapse cavity above the tunnel have significant 


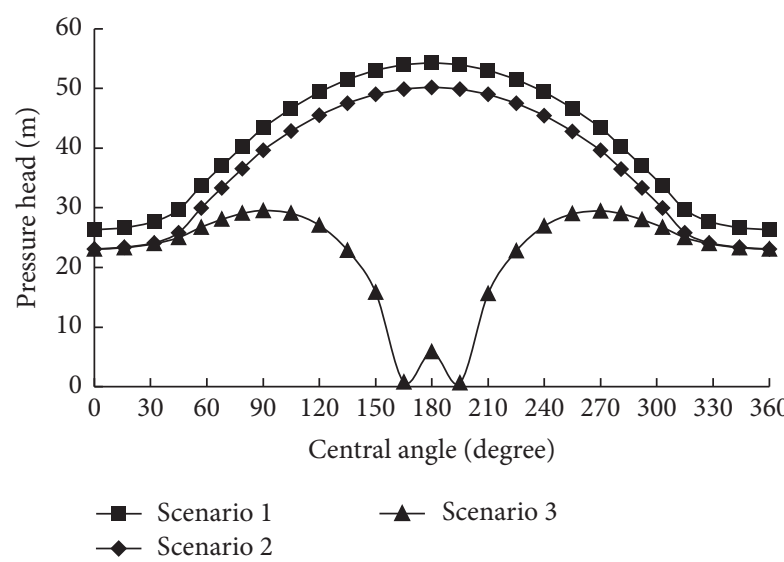

(a)

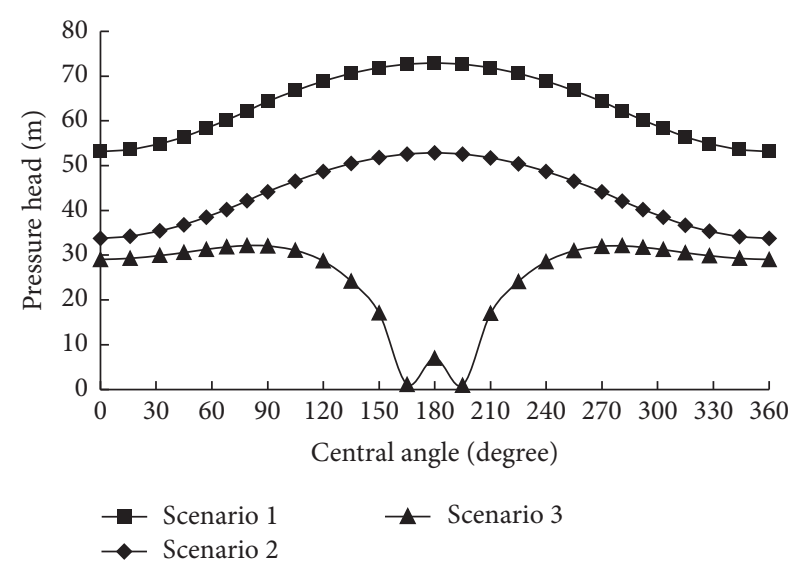

(b)

Figure 13: Comparison of the external pressure head on the steel lining in the three scenarios: (a) at section $0+37.0 \mathrm{~m}$ and (b) at section $0+27.0 \mathrm{~m}$.

influences on the distribution of the seepage field at the collapse zone. The adopted antiseepage curtain and drain holes effectively improve the seepage environment at the collapse zone, limit the external water pressure on the steel lining to a critical external compressive resistance of $0.68 \mathrm{MPa}$, and ensure the safety and stability of the steel lining during the operating period.

\section{Conclusions}

(1) When treating a large-scale collapse in the steel-lined pressure diversion tunnel by consolidation grouting of the loose collapse body within a certain thickness range, the stability of the steel lining under the internal and external water pressure during the operating period should be considered, in addition to the stability of the surrounding rocks at the collapse zone during the construction period.

(2) In considering the fact that the steel lining and the consolidation layer bear the internal water pressure jointly, a joint element and the load-sharing ratio of the consolidation layer are introduced to investigate the joint loadbearing characteristics with consolidation layer thicknesses from $0 \mathrm{~m}$ (without consolidation grouting) to $30 \mathrm{~m}$ (i.e., complete backfilling). The results show that the thickness of the consolidation layer affects the joint load-bearing characteristics and the stability of the steel lining; however, when the thickness exceeds $10 \mathrm{~m}$, there is no obvious change in the effect of the consolidation layer on the stability of the steel lining; the load-sharing performance of a $10 \mathrm{~m}$ thick consolidation layer is almost the same as that of the complete backfilling, which ensures the stability and safety of the steel lining when it is subjected to internal water pressure during the operating period. Therefore, $10 \mathrm{~m}$ is determined as the thickness of the consolidation layer. The adopted analysis method is of guiding significance for designing the thickness of the consolidation layer and assessing the stability of the steel lining under the internal water pressure at the collapse zone.
(3) By considering the influences of internal water exosmosis and the collapse cavity on the distribution of the seepage field at the collapse zone, a coupling method for simulating the hydromechanical interaction of the reinforced concrete lining is adopted to investigate the distribution of the seepage field at the collapse zone. The results show that the collapse cavity as the overflow boundary can reduce the water head at the collapse zone; however, internal water exosmosis generates an internal source of seepage, which increases the external water head on the steel lining until it exceeds the critical external compressive resistance of the adopted steel lining. Therefore, an antiseepage curtain is placed between the reinforced concrete lining and the steel lining to diminish the effect of internal water exosmosis on the collapse zone, and two rows of drain holes are placed at the bottom to decrease the external water pressure on the steel lining. The analysis method adopted here is of guiding significance in the quantitative analysis of the distribution of a seepage field under complex conditions, the design of antiseepage measures, and the stability analysis of steel lining under external water pressure at a collapse zone.

\section{Conflicts of Interest}

The authors declare that there are no conflicts of interest regarding the publication of this paper.

\section{Acknowledgments}

This study is supported by the National Key Basic Research Program of China (2015CB057904) and the National Natural Science Foundation of China (51279136 and 51579191). This support is greatly acknowledged and appreciated.

\section{References}

[1] C. O. Aksoy and T. Onargan, "The role of umbrella arch and face bolt as deformation preventing support system in 
preventing building damages," Tunnelling and Underground Space Technology, vol. 25, no. 5, pp. 553-559, 2010.

[2] K. Miura, "Design and construction of mountain tunnels in Japan," Tunnelling and Underground Space Technology, vol. 18, no. 2-3, pp. 115-126, 2003.

[3] H.-S. Shin, Y.-C. Kwon, Y.-S. Jung, G.-J. Bae, and Y.-G. Kim, "Methodology for quantitative hazard assessment for tunnel collapses based on case histories in Korea," International Journal of Rock Mechanics and Mining Sciences, vol. 46, no. 6, pp. 10721087, 2009.

[4] J.-A. Wang, H. D. Park, and Y. T. Gao, "A new technique for repairing and controlling large-scale collapse in the main transportation shaft, Chengchao iron mine, China," International Journal of Rock Mechanics and Mining Sciences, vol. 40, no. 4, pp. 553-563, 2003.

[5] Z.-Q. Zhou, S.-C. Li, L.-P. Li, B. Sui, S.-S. Shi, and Q.-Q. Zhang, "Causes of geological hazards and risk control of collapse in shallow tunnels," Rock and Soil Mechanics, vol. 34, no. 5, pp. 1375-1382, 2013.

[6] C. Kong, X. Q. Gao, L. Cao, and K. Liu, "Analysis of the failure of primary support of a deep-buried railway tunnel in silty clay," Engineering Failure Analysis, vol. 66, pp. 259-273, 2016.

[7] S. Türkmen and N. Özgüzel, "Grouting a tunnel cave-in from the surface: a case study on Kurtkulağ 1 irrigation tunnel, Turkey," Tunnelling and Underground Space Technology, vol. 18, no. 4, pp. 365-375, 2003.

[8] B. Nilsen, "Cases of instability caused by weakness zones in Norwegian tunnels," Bulletin of Engineering Geology and the Environment, vol. 70, no. 1, pp. 7-13, 2011.

[9] G. Fernández, "Behavior of pressure tunnels and guidelines for liner design," Journal of Geotechnical Engineering, vol. 120, no. 10, pp. 1768-1791, 1994.

[10] K. Bian, M. Xiao, and J. Chen, "Study on coupled seepage and stress fields in the concrete lining of the underground pipe with high water pressure," Tunnelling and Underground Space Technology, vol. 24, no. 3, pp. 287-295, 2009.

[11] K. Su and H.-G. Wu, "Nonlinear finite element analysis of reinforced concrete lining of hydraulic tunnels," Rock and Soil Mechanics, vol. 26, no. 9, pp. 1485-1490, 2005.

[12] Y. F. Zhou, K. Su, and H. G. Wu, "Hydro-mechanical interaction analysis of high pressure hydraulic tunnel," Tunnelling and Underground Space Technology, vol. 47, pp. 28-34, 2015.

[13] Q. Y. Zhang and Y. T. Yu, "Numerical simulation analysis of interaction between lining and surrounding rockmass for pressure tunnel," Engineering Journal of Wuhan University, vol. 31, pp. 18-21, 1998.

[14] J. Chen, Y. Yang, C. Ye, Y. Yang, and M. Xiao, “Three-dimensional numerical analysis of compound lining in complex underground surge-shaft structure," Mathematical Problems in Engineering, vol. 2015, Article ID 387379, 10 pages, 2015.

[15] K. Wang, D. C. Jansen, S. P. Shah, and A. F. Karr, "Permeability study of cracked concrete," Cement and Concrete Research, vol. 27, no. 3, pp. 381-393, 1997.

[16] G. Pijaudier-Cabot, F. Dufour, and M. Choinska, "Permeability due to the increase of damage in concrete: from diffuse to localized damage distributions," Journal of Engineering Mechanics, vol. 135, no. 9, pp. 1022-1028, 2009.

[17] B. A. Olumide, "Numerical coupling of stress and seepage in the design of pressure tunnel under to high internal water pressure," International Journal of Engineering and Technology, vol. 3, no. 3, pp. 235-244, 2013.
[18] Y. Chen, R. Hu, C. Zhou, D. Li, and G. Rong, "A new parabolic variational inequality formulation of Signorini's condition for non-steady seepage problems with complex seepage control systems," International Journal for Numerical and Analytical Methods in Geomechanics, vol. 35, no. 9, pp. 1034-1058, 2011.

[19] Y. Q. Wu, "Types of rock mass structure and hydromechanical models in rock mass," Chinese Journal of Rock Mechanics and Engineering, vol. 19, pp. 687-691, 2000.

[20] M. Xiao, Z.-H. Fu, and C. Ye, "Numerical analysis of influence of seepage from underground conduit lining under high internal water pressure on slope stability," Rock and Soil Mechanics, vol. 28, no. 2, pp. 302-306, 2007.

[21] Q. Q. Ran and X. Y. Gu, "Coupling analysis of multiphase flow and stress for oil reservoir," Chinese Jounal of Geotechnical Engineering, vol. 20, pp. 69-73, 1998.

[22] T. Wang, H. Wu, Y. Li et al., "Stability analysis of the slope around flood discharge tunnel under inner water exosmosis at Yangqu hydropower station," Computers and Geotechnics, vol. 51, pp. 1-11, 2013. 


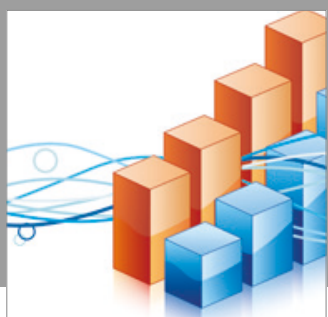

Advances in

Operations Research

vatersals

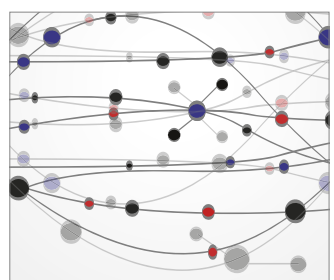

\section{The Scientific} World Journal
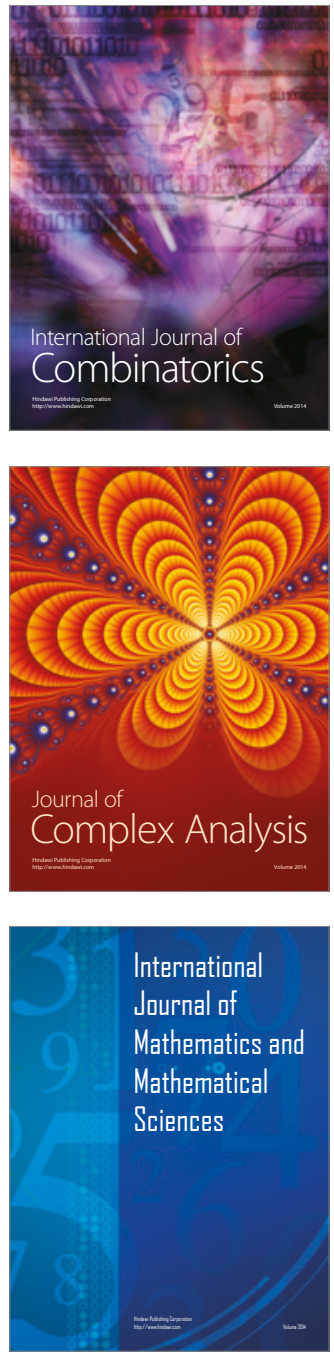
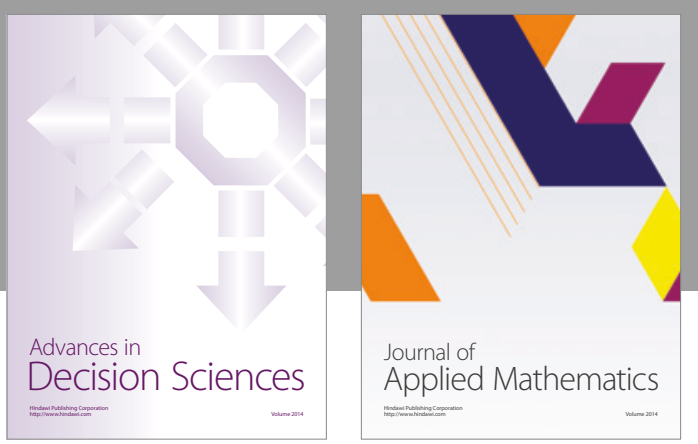

Algebra

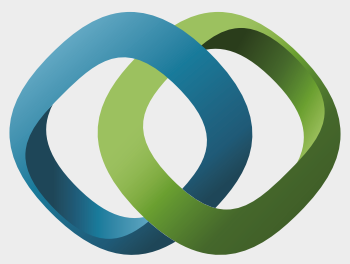

\section{Hindawi}

Submit your manuscripts at

https://www.hindawi.com
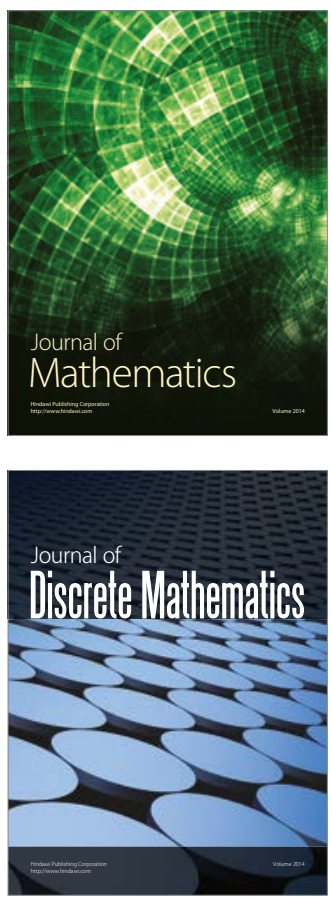

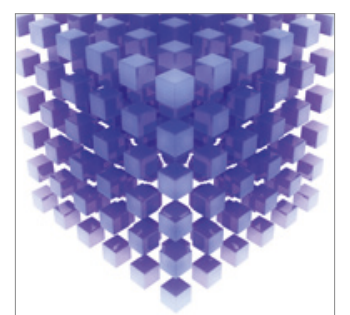

Mathematical Problems in Engineering
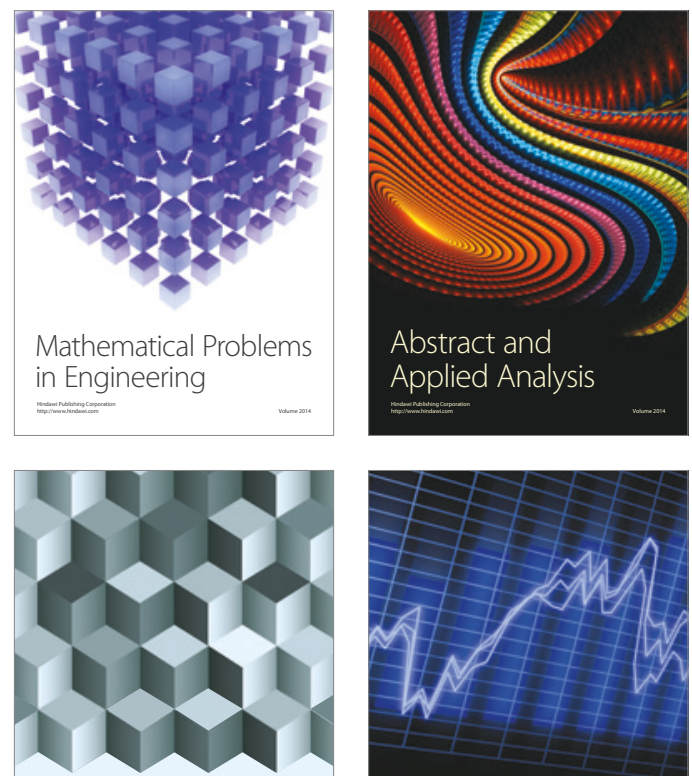

Journal of

Function Spaces

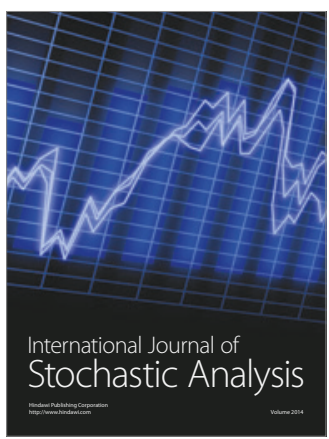

Probability and Statistics
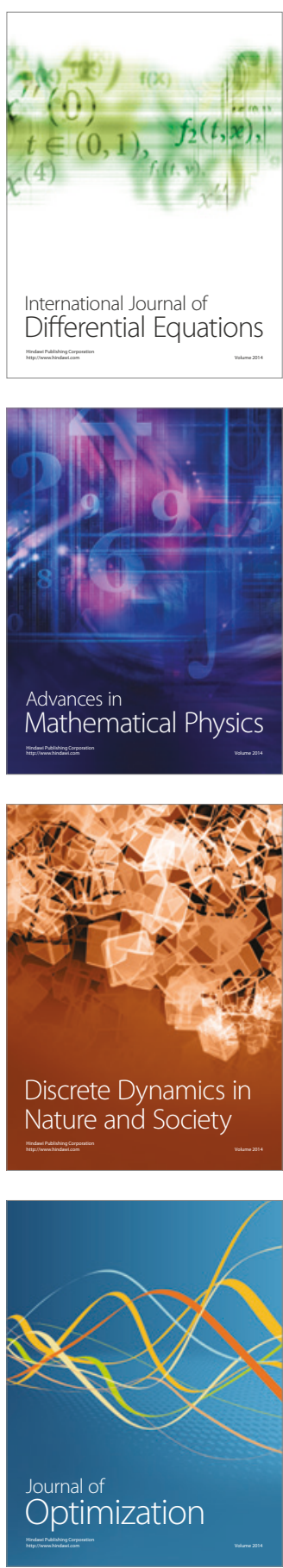